\title{
The atypical iron-coordination geometry of cytochrome $f$ remains unchanged upon binding to plastocyanin, as inferred by XAS
}

\author{
Irene Díaz-Moreno · Sofía Díaz-Moreno · \\ Gloria Subías · Miguel A. De la Rosa • \\ Antonio Díaz-Quintana
}

Received: 8 July 2006/ Accepted: 25 August 2006/Published online: 17 November 2006

(C) Springer Science+Business Media B.V. 2006

\begin{abstract}
The transient complex between cytochrome $f$ and plastocyanin from the cyanobacterium Nostoc sp. PCC 7119 has been analysed by X-ray Absorption Spectroscopy in solution, using both proteins in their oxidized and reduced states. Fe K-edge data mainly shows that the atypical metal coordination geometry of cytochrome $f$, in which the N-terminal amino acid acts as an axial ligand of the heme group, remains unaltered upon binding to its redox partner, plastocyanin. This fact suggests that cytochrome $f$ provides a stable binding site for plastocyanin and minimizes the reorganization energy required in the transient complex formation, which could facilitate the electron transfer between the two redox partners.
\end{abstract}

Díaz-Moreno · M. A. De la Rosa · A. Díaz-Quintana Instituto de Bioquímica Vegetal y Fotosíntesis, Universidad de Sevilla y Consejo Superior de Investigaciones Científicas, Américo Vespucio 49, 41092 Sevilla, Spain

\section{S. Díaz-Moreno}

Rutherford Appleton Laboratory, Diamond Light Source Ltd., Chilton, Didcot, Oxfordshire OX11 0QX, UK

\section{G. Subías}

Departamento de Física de la Materia Condensada, Instituto de Ciencia de Materiales de Aragón, Universidad de Zaragoza y Consejo Superior de Investigaciones Científicas, Plaza San Francisco s/n, 50009 Zaragoza, Spain

I. Díaz-Moreno ( $₫)$

National Institute for Medical Research, Molecular

Structure Division, The Ridgeway, Mill Hill, NW7 1AA

London, UK

e-mail: irene.diazmoreno@nimr.mrc.ac.uk
Keywords Cytochrome $f \cdot$ Electron transfer · Metalloproteins · Plastocyanin · Transient complexes · $\mathrm{X}$-ray absorption spectroscopy

$\begin{array}{ll}\text { Abbreviations } \\ \text { Cf } & \text { water-soluble fragment of cytochrome } f \\ \text { ET } & \text { electron transfer } \\ \text { EXAFS } & \text { extended X-ray absorption fine structure } \\ \text { FT } & \text { Fourier transform } \\ \text { Pc } & \text { plastocyanin } \\ \text { XANES } & \text { X-ray absorption near edge structure } \\ \text { XAS } & \text { X-ray absorption spectroscopy } \\ \text { XRD } & \text { X-Ray diffraction } \\ \Delta E_{0} & \text { internal potential correction } \\ \Delta r & \text { change in the distance between the metal } \\ & \text { and ligand atoms } \\ \sigma & \text { Debye-Waller parameter related to the } \\ & \text { system dynamic disorder }\end{array}$

\section{Introduction}

In oxygen-evolving photosynthetic organisms, the cytochrome $b_{6}-f$ complex couples proton translocation across the thylacoid membrane to the electron transport between photosystems I and II (Allen 2004). In this complex, cytochrome $f(\mathrm{C} f)$ transfers electrons from the Rieske iron sulphur cluster to a soluble metalloprotein that acts as the immediate electron donor of P700 cofactor at Photosystem I.

The $\mathrm{C} f$ subunit consists on a $28.2 \mathrm{kDa} \mathrm{N}$-terminal soluble domain anchored to the membrane by C-terminal helix (Gray 1992). Its soluble domain is an 
atypical $c$-type cytochrome because both its $\beta$-sheet secondary structure and the unusual heme axial coordination (Martinez et al. 1994) with the N-terminal amino acid Tyr-1 acting as an axial ligand.

The most ubiquitous electron carrier between $\mathrm{C} f$ and P700 is plastocyanin (Pc) (Sandman et al. 1983), which is a type I cupredoxin (Gough and Chotia 2004). Its structure consists on an anti-parallel $\beta$-barrel with a single copper atom (Coleman et al. 1978; Sykes 1985; Redinbo et al. 1994) coordinated by two nitrogen atoms and two sulphur ones from highly conserved residues (H39, C89, H92 and M97 in Nostoc cyanobacterium).

The mechanism of the electron transfer (ET) reaction between Pc and its physiological partners has been studied extensively (Hope 2000; Hervás et al. 2003; Díaz-Quintana et al. 2003) highlighting the role of electrostatic and hydrophobic interactions on binding. Also, the solution structures of several Pc-C $f$ complexes have been reported (Ubbink 2004; DíazMoreno et al. 2005a, Lange et al. 2005; Musiani et al. 2005). In all the cases, these structures are consistent with a single conformation ensemble in which the hydrophobic patch surrounding Tyr- 1 in $\mathrm{C} f$ docks the hydrophobic patch of Pc.

Despite the large amount of data concerning the nature of the interactions influencing the binding between the redox partners, little is known about the effects of complex formation on the metal cofactors, and how they can modulate the ET process. An analysis about whether the $\mathrm{Fe}$ coordination in $\mathrm{C} f$ is altered upon binding to $\mathrm{Pc}$ would be interesting to address the above-mentioned effects, especially due to the fact that the N-terminal amino acid Tyr-1, which is involved in the Pc-Cf interface (Ubbink 2004; Díaz-Moreno et al. 2005a, Lange et al. 2005; Musiani et al. 2005), acts as axial ligand. To get a deep insight on these subjects we have studied the $\mathrm{Fe}$ K-edge of free and Pc-bound $\mathrm{C} f$ by X-ray absorption spectroscopy (XAS) in solution.

\section{Materials and methods}

\section{Protein samples}

Nostoc sp. PCC 7119 Pc was purified from E. coli cells transformed with the pEAP-WT plasmid (MolinaHeredia et al. 1998). Production and purification of the soluble domain of Nostoc sp. PCC $7119 \mathrm{C} f$ were as previously described (Albarrán et al. 2005).

For the XAS experiments, the Pc and $\mathrm{C} f$ samples were concentrated to the required volume by ultrafil- tration methods, and exchanged into $10 \mathrm{mM}$ sodium phosphate $\mathrm{pH}$ 6.0. After concentration, stock solutions of $10 \mathrm{mM} \mathrm{Pc}$ and $4.5 \mathrm{mM} \mathrm{C} f$ were obtained. Protein concentration was determined by optical spectroscopy using an absorption coefficient of $4.5 \mathrm{mM}^{-1} \mathrm{~cm}^{-1}$ at $598 \mathrm{~nm}$ for oxidized Pc (Molina-Heredia et al. 1998) and $31.5 \mathrm{mM}^{-1} \mathrm{~cm}^{-1}$ at $556 \mathrm{~nm}$ for reduced $\mathrm{C} f$ (Albarrán et al. 2005). Oxidized $\mathrm{C} f\left(\mathrm{C} f^{\mathrm{III}}\right)$ was prepared by adding an equimolecular amount of potassium ferricyanide, followed by gel filtration in a Pharmacia Superdex G75 column to remove ferrocyanide. Reduced $\mathrm{C} f\left(\mathrm{C} f{ }^{\mathrm{II}}\right)$ was obtained upon addition of a tenfold excess of sodium ascorbate to a resulting Cf ${ }^{\text {III }}$ sample. Oxidized $\mathrm{Pc}\left(\mathrm{Pc}^{\mathrm{II}}\right)$ was obtained by addition of either ferricyanide, as described for $\mathrm{C} f$. The oxidized complex $\left(\mathrm{Pc}^{\mathrm{II}}-\mathrm{C} f^{\mathrm{III}}\right)$ was prepared by adding an aliquot of a $10 \mathrm{mM} \mathrm{Pc}{ }^{\mathrm{II}}$ onto a $\mathrm{C} f^{\mathrm{III}}$ sample up to reach a final concentration of ca. $2 \mathrm{mM}$ each. Under these conditions, the percentage of Pc bound to $\mathrm{C} f$ was estimated to be ca. $87 \%$, according to the binding constant calculated from NMR data (Díaz-Moreno et al., 2005a). The reduced complex ( $\left.\mathrm{Pc}^{\mathrm{I}}-\mathrm{C} f{ }^{\mathrm{II}}\right)$ was obtained upon addition of a tenfold excess of sodium ascorbate to a $\mathrm{Pc}^{\mathrm{II}}-\mathrm{C} f{ }^{\mathrm{III}}$ sample prepared as above.

\section{XAS measurements}

The X-ray absorption spectra were recorded at the European Synchrotron Radiation Facility (ESRF) in Grenoble (France), which was operating with a ring current of $200 \mathrm{~mA}$ and energy of $6 \mathrm{GeV}$. The $\mathrm{Fe}$ K-edge $(7112 \mathrm{eV})$ was measured at beam line BM29 using a double crystal monochromator fitted with a pair of flat Si (311) crystals detuned to $50 \%$ fwhm of the maximum transmission, for the suppression of high energy harmonics.

All measurements were made at room temperature in fluorescence mode, using a 13-element Canberra solid-state germanium detector. The samples were contained in a PTFE cell equipped with two $12 \mu \mathrm{m}$ Kapton foil windows.

Energy calibration was achieved by measuring an iron foil for the Fe edge. The spectra of the foil were measured simultaneously, with the data in transmission mode, to be used as an internal reference. Ionization chambers filled with the appropriate mixture of gases were used as detectors.

For all measurements, each data point was collected for $4 \mathrm{~s}$, and several scans were averaged to achieve a good signal-to-noise ratio. In no case protein photoreduction or damage was observed, even in those samples in which the measurements were made over several hours. For the oxidized forms free and 
Pc-bound $\mathrm{C} f$, the edge remained at fix energy position from the first to the last scan, thus confirming the absence of protein photoreduction. The lack of radiation-induced changes in the samples was also confirmed by UV-vis measurements before and after XAS measurements.

\section{XAS data analysis}

The background subtraction required to obtain the extended X-ray absorption fine structure (EXAFS) functions $\chi(\mathrm{k})$ from the measured X-ray absorption spectra were performed using the AUTOBK code from the University of Washington. $E_{0}$ was defined as the maximum of the first derivative of the absorption edge.

To analyze the EXAFS spectra, the theoretical phases and amplitudes were calculated using the FEFF 6.0 code (Rehr et al. 1992; Newville et al. 1995). The fit to the experimental data was performed using the FEFFIT program (version 2.54) (Newville et al. 1995).

\section{Results and discussion}

\section{XANES region}

Figure 1 (upper panel) shows the X-ray absorption near edge structure (XANES) spectra corresponding to free $\mathrm{C} f$ in its reduced and oxidized states. In both spectra there is a pre-edge feature corresponding to the forbidden transition $1 s-3 d$, which is sensitive to the electronic and geometric structure of the atom $(\mathrm{Fe})$ site (Westre et al. 1997). In fact, the intensity of this transition agrees with the octahedral environment around the iron atom in C $f$ (Martinez et al. 1994).

On the other hand, the edge position, determined by the maximum in the first derivative of the absorption spectrum corresponding to free $\mathrm{C} f$, , appears ca. $1 \mathrm{eV}$ below that of $\mathrm{C} f^{\mathrm{III}}$, as previously found for the reduced and oxidized states of two closely related proteins, as heart cytochrome $c$ (Cheng et al. 1999) and Nostoc cytochrome $c_{6}$ (Díaz-Moreno et al. 2006). In case of cytochrome $c$ (Cheng et al. 1999), photoreduction of the oxidized species was observed only after the 16th spectrum of the series. In our case, however, there is no photoreduction as inferred from the fact that the edge position remains fixed for all the spectra along each series i.e. reduced or oxidized, free or bound. The reason not to observe any sample photo-reduction is due to the moderate brightness of the EXAFS spectrometer deliberately chosen for this investigation. In addition, the same shift has also been reported upon
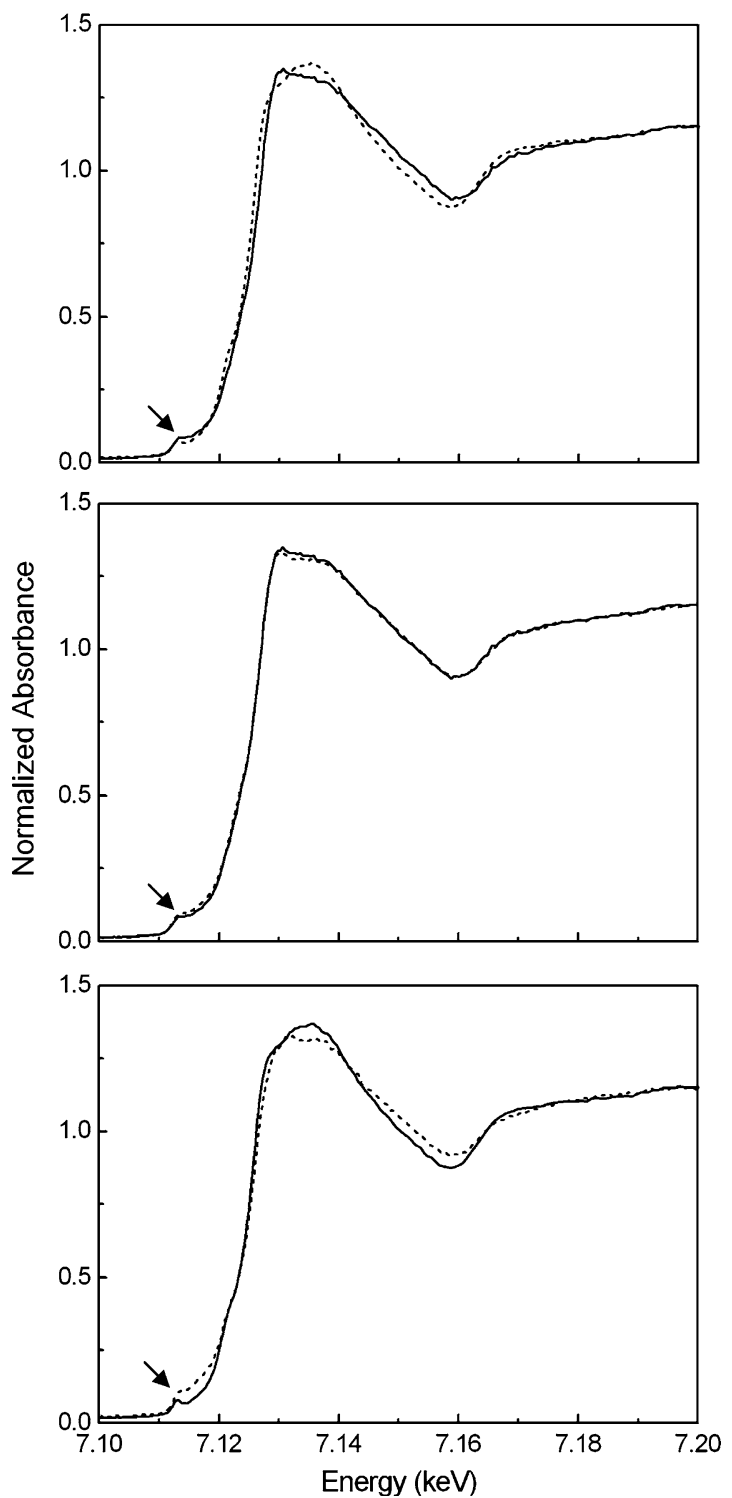

Fig. 1 XANES region of the Fe K-edge XAS spectra of free and Pc-bound Cf. Upper, experimental data for oxidized and reduced forms of free proteins, $\mathrm{C} f^{\mathrm{III}}$ (continuous line) and $\mathrm{C} f^{\mathrm{II}}$ (dashed line). Middle, data for the oxidized species, $\mathrm{C} f$ III (continuous line) and $\mathrm{Pc}^{\mathrm{II}}-\mathrm{C} f$ III complex (dashed line). Lower, data for the reduced species, $\mathrm{C} f{ }^{\mathrm{II}}$ (continuous line) and $\mathrm{Pc}-\mathrm{C} f^{\mathrm{II}}$ complex (dashed line). The presence of a pre-edge signal at $7113 \mathrm{eV}$ is marked by arrows

oxidation from $\mathrm{Fe}^{2+}$ to $\mathrm{Fe}^{3+}$ at $\mathrm{pH} 7$ in the heme protein cytochrome $c$ (Shulman et al. 1976).

Moreover, there are some differences in both XANES spectra, particularly in the first feature after the edge.

Figure 1 also shows the XANES regions of the absorption spectra of $\mathrm{C} f$ bound to $\mathrm{Pc}$ in the oxidized and reduced state. The XANES region of the absorption spectra for $\mathrm{Pc}^{\mathrm{II}}-\mathrm{C} f{ }^{\mathrm{III}}$ and $\mathrm{C} f^{\mathrm{III}}$ are identical (Fig. 1, middle panel), indicating that the electronic 
and geometrical configuration around the iron centre remains unchanged when bound to Pc. However, this is not the case for the reduced proteins (Fig. 1, lower panel). In fact, the spectrum of the $\mathrm{Pc}^{\mathrm{I}}-\mathrm{C} f{ }^{\mathrm{II}}$ complex exhibits some differences compared with that of free $\mathrm{C} f^{\mathrm{I}}$. With regard to the pre-edge, a slight increase in the intensity of this feature is observed for $\mathrm{C} f{ }^{\mathrm{II}}$ when bound to $\mathrm{Pc}^{\mathrm{I}}$, according to the decrease in electron density of the Fe atom. The shape of the first feature after the edge slightly changes too, thus suggesting certain modifications in the geometrical distribution of the ligands around the iron atom. It is worth noting that the spectrum of the reduced complex is very similar-except for the pre-edge signal and edge position-to that of the oxidized complex and free oxidized $\mathrm{C} f$, as shown in Fig. 3. This suggests that the iron geometry in reduced $\mathrm{C} f$ is distorted upon association to $\mathrm{Pc}$, approaching to that of the iron centre in the oxidized form, either free or bound to Pc.

\section{EXAFS Region}

The extracted EXAFS signals of $\mathrm{C} f$ in the reduced and oxidized states are shown in Fig. 2 (left panels) as $\mathrm{k}$-weighted spectra. The choice of a $k$-weighting instead of a $k^{3}$-weighting is based on the following facts. First, we were interested in determining the local environment around the absorbing atom and, in particular, at the first coordination shell. This shell is formed by iron and light elements, such as nitrogen, and their backscattering amplitude drops quickly at increasing energy ( $k$ value). Therefore, they have a larger contribution when the transforms are made in $\mathrm{k}$ rather than in $k^{3}$. Second, if a $k^{3}$-weighting is used, the highest energy part of the spectrum is emphasized and, in this case, the EXAFS signal would be dominated by the spectral region where the signal-to-noise ratio is poorer.

We should note here that the XAS data were collected at room temperature in order to maintain consistency with previous room temperature NMR measurements made on the same systems (Díaz-Moreno et al. 2005a, b). Although a better signal to noise should be obtained at cryogenic temperatures, the transient complexes we study are not stable upon freezing, unless the partners are chemically cross-linked. Similar experimental conditions are required by EPR. Although EPR measurements on free and Pc-bound $\mathrm{C} f$ would help to study the iron geometry, any comparison between results inferred from NMR or XAS, on one hand, and EPR, on the other, would be unreliable.

As can be seen, the EXAFS function is not a simple wave but a combination of different waves
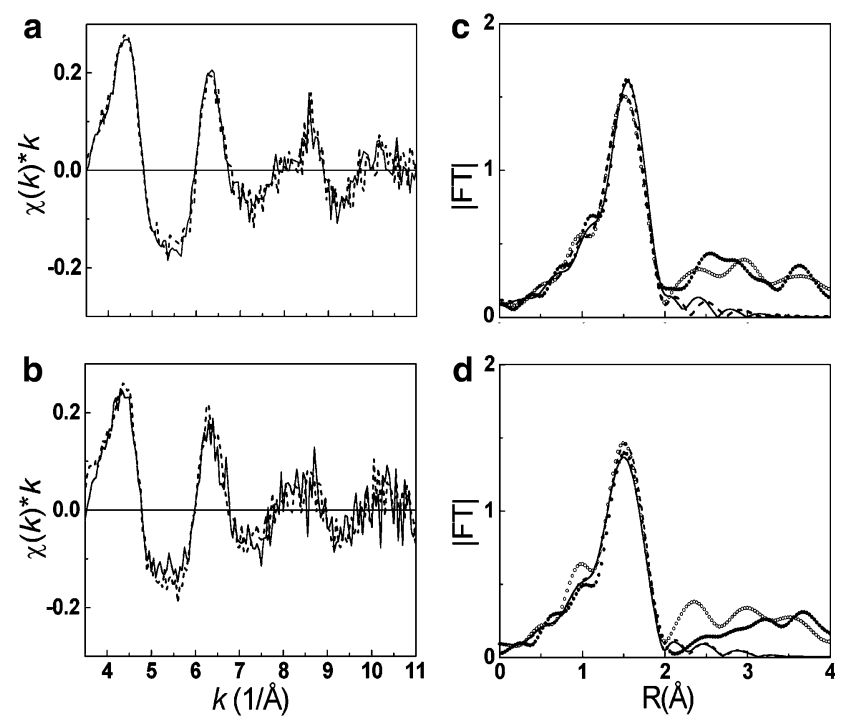

Fig. 2 EXAFS data (panels a and b) and their FT modules (panels $\mathrm{c}$ and $\mathrm{d}$ ) at the Fe K-edge of $\mathrm{C} f$, either free or bound to Pc. The EXAFS spectra of free proteins $\left(\mathrm{C} f^{\text {II }}\right.$ and $\left.\mathrm{C} f^{\mathrm{III}}\right)$ are shown in panel a by continuous line for $\mathrm{C} f$ II and dashed line for $\mathrm{C} f$ III. In panel b, the EXAFS spectra of $\mathrm{Pc}^{\mathrm{I}}-\mathrm{C} f^{\mathrm{II}}$ and $\mathrm{Pc}{ }^{\mathrm{II}}-\mathrm{C} f^{\mathrm{III}}$ complexes are represented by continuous and dashed lines, respectively. The corresponding FT modules of the EXAFS spectra for free $\mathrm{C} f\left(\mathrm{C} f^{\mathrm{II}}\right.$ and $\left.\mathrm{C} f{ }^{\mathrm{III}}\right)$ are represented in panel $\mathbf{c}$ by closed and open circles, respectively. Panel d shows the FT modules for Pc-bound $\mathrm{C} f$ forms: $\mathrm{Pc}-\mathrm{C} f{ }^{\mathrm{II}}$ by closed circles and $\mathrm{Pc}^{\mathrm{II}}-\mathrm{C} f^{\mathrm{III}}$ by open circles. The best fits of the FT data for both reduced $\left(\mathrm{C} f^{\mathrm{II}}\right.$ and $\left.\mathrm{Pc}-\mathrm{C} f^{\mathrm{II}}\right)$ and oxidized states $\left(\mathrm{C} f^{\mathrm{III}}\right.$ and $\mathrm{Pc}^{\mathrm{II}}-$ $\mathrm{C} f$ III $)$ are represented by continuous and dashed lines, respectively

corresponding to the contributions from the neighbouring atoms at different distances around the iron centre. Indeed, the EXAFS signals of $\mathrm{C} f$ do not change upon binding to Pc, thereby indicating that the local coordination environment around the iron centre remains unchanged.

The Fourier Transform (FT) of the corresponding spectra and the best fits, obtained with the parameters included in Table 1, are also shown in Fig. 2 (right panels). As a starting model, the values obtained from the X-ray diffraction (XRD) structure of Phormidium $\mathrm{C} f$ (Carrel et al. 1999) were used. In all cases there is a main signal around $1.5 \AA$, which corresponds to the first coordination sphere formed by the four nitrogen atoms of the porphyrin ring (NA, NB, NC and ND), along with the nitrogen atoms of the two iron axial ligands Tyr-1 $(\mathrm{N})$ and His-26 $\left(\mathrm{N}_{\varepsilon 2}\right)$. The intensities of the remaining signals are significantly lower than the first one because they correspond to contributions from lightweight elements lying at longer coordination distances. In order to fit the data, six simple scattering paths from the $\mathrm{Fe}$ atom to the six ligand $\mathrm{N}$ atoms were selected. $\Delta r_{1}$ and $\Delta r_{2}$ were used as two fitting 
parameters corresponding to changes in the distances of Fe to the two axial $\mathrm{N}$ atoms and to the four phorphyrin $\mathrm{N}$ atoms, respectively. The Debye-Waller parameter, $\sigma^{2}$, related to system dynamic disorder was also fitted, with $\sigma_{1}^{2}$ accounting for the bonds between the $\mathrm{Fe}$ atom and the two axial $\mathrm{N}$ atoms and $\sigma_{2}^{2}$ accounting for the bonds between the $\mathrm{Fe}$ atom and the four porphyrin $\mathrm{N}$ atoms. The fifth adjustable parameter was the internal potential correction $\left(\Delta E_{0}\right)$.

Although there are no significant changes in the metal-ligand distances, the Fe K-edge X-ray absorption data suggests a small distortion of the $\mathrm{Fe}^{2+}$ metal centre geometry when $\mathrm{C} f^{\mathrm{II}}$ binds to $\mathrm{Pc}^{\mathrm{I}}$. The resulting $\mathrm{Fe}^{2+}$ geometry resembles that of $\mathrm{C} f{ }^{\mathrm{III}}$, either free or bound to $\mathrm{Pc}^{\mathrm{II}}$ (Fig. 3). Although the $\mathrm{Fe}$ atom of $\mathrm{C} f$ shows a well-defined position at the heme group, which provides a rigid frame, the small distortion on the $\mathrm{Fe}^{2+}$ metal centre when $\mathrm{C} f{ }^{\mathrm{II}}$ binds to $\mathrm{Pc}^{\mathrm{I}}$ can be explained by the smaller size of $\mathrm{Fe}^{3+}$ compared to $\mathrm{Fe}^{2+}$ : The $\mathrm{Fe}^{3+}$ atom fits well into the heme ring whereas the $\mathrm{Fe}^{2+}$ atom is somewhat shifted out of the plane (Schnackenberg et al. 1999); however, the $\mathrm{Fe}^{2+}$ atom could be driven into the ring upon complex formation, thus yielding a structure of $\mathrm{Pc}^{\mathrm{I}}$-bound $\mathrm{Fe}^{2+}$ similar to that of $\mathrm{Fe}^{3+}$ in free and $\mathrm{Pc}^{\mathrm{II}}$-bound $\mathrm{C} f$ III.

Table 1 Best-fit structural parameters resulted from the EXAFS analysis for free and Pc-bound C $f$, in both oxidized and reduced state

\begin{tabular}{|c|c|c|c|c|}
\hline System & Ligand & $\Delta E_{0}(\mathrm{eV})$ & $\mathrm{r}(\mathrm{M}-\mathrm{L})(\AA)$ & $\sigma^{2}(\mathrm{M}-\mathrm{L})\left(\AA^{2}\right)$ \\
\hline \multirow[t]{5}{*}{$\mathrm{C} f^{\mathrm{III}}$} & $\mathrm{N}(\mathrm{NC})$ & $-7 \pm 4$ & $1.96 \pm 0.02$ & $0.002 \pm 0.001$ \\
\hline & N (NA \& ND) & & $1.97 \pm 0.02$ & \\
\hline & $\mathrm{N}(\mathrm{NB})$ & & $1.98 \pm 0.02$ & \\
\hline & $\mathbf{N}\left(\mathbf{N}_{\varepsilon 2}\right)$ & & $2.44 \pm 0.06$ & $0.010 \pm 0.010$ \\
\hline & $\mathrm{N}(\mathrm{N})$ & & $2.49 \pm 0.06$ & \\
\hline \multirow[t]{5}{*}{$\mathrm{C} f^{\mathrm{II}}$} & $\mathrm{N}(\mathrm{NC})$ & $-6 \pm 2$ & $1.97 \pm 0.01$ & $0.002 \pm 0.001$ \\
\hline & N (NA \& ND) & & $1.99 \pm 0.01$ & \\
\hline & $\mathrm{N}(\mathrm{NB})$ & & $2.00 \pm 0.01$ & \\
\hline & $\mathbf{N}\left(\mathbf{N}_{\varepsilon 2}\right)$ & & $2.43 \pm 0.02$ & $0.004 \pm 0.003$ \\
\hline & $\mathrm{N}(\mathrm{N})$ & & $2.48 \pm 0.02$ & \\
\hline \multirow[t]{5}{*}{$\mathrm{Pc}^{\mathrm{II}}-\mathrm{C} f^{\mathrm{III}}$} & $\mathrm{N}(\mathrm{NC})$ & $-7 \pm 3$ & $1.97 \pm 0.01$ & $0.002 \pm 0.001$ \\
\hline & $\mathrm{N}(\mathrm{NA} \& \mathrm{ND})$ & & $1.98 \pm 0.01$ & \\
\hline & $\mathrm{N}(\mathrm{NB})$ & & $1.99 \pm 0.01$ & \\
\hline & $\mathbf{N}\left(\mathrm{N}_{\varepsilon 2}\right)$ & & $2.40 \pm 0.03$ & $0.011 \pm 0.009$ \\
\hline & $\mathrm{N}(\mathrm{N})$ & & $2.45 \pm 0.03$ & \\
\hline \multirow[t]{5}{*}{$\mathrm{Pc}^{\mathrm{I}}-\mathrm{C} f^{\mathrm{II}}$} & $\mathrm{N}(\mathrm{NC})$ & $-6 \pm 3$ & $1.97 \pm 0.02$ & $0.003 \pm 0.001$ \\
\hline & $N(N A \& N D)$ & & $1.98 \pm 0.02$ & \\
\hline & $\mathrm{N}(\mathrm{NB})$ & & $1.99 \pm 0.02$ & \\
\hline & $\mathbf{N}\left(\mathbf{N}_{\varepsilon 2}\right)$ & & $2.40 \pm 0.03$ & $0.010 \pm 0.009$ \\
\hline & $\mathrm{N}(\mathrm{N})$ & & $2.45 \pm 0.03$ & \\
\hline
\end{tabular}

$\mathrm{S}_{0}^{2}$, factor of amplitude of reduction; $\mathrm{r}(\mathrm{M}-\mathrm{L})$, metal-ligand distance

$\mathrm{S}_{0}^{2}=1.0, \Delta k=3.5-11(1 / \AA), \Delta \mathrm{R}=1.1-2.1(\AA), R$ factor $($ free $\left.\mathrm{C} f^{\mathrm{III}}\right)=0.044, R$ factor (free $\left.\mathrm{C} f^{\mathrm{II}}\right)=0.004, \mathrm{R}$ factor $\left(\mathrm{Pc}^{\mathrm{II}}-\right.$ bound $\left.\mathrm{C} f^{\mathrm{III}}\right)=0.004, R$ factor $\left(\mathrm{Pc}^{\mathrm{I}}\right.$-bound $\left.\mathrm{C} f^{\mathrm{II}}\right)=0.003$

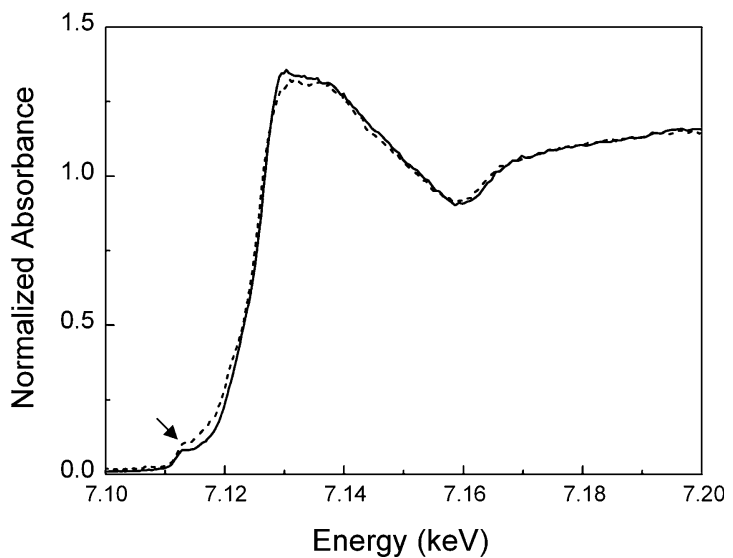

Fig. 3 XANES region of the Fe K-edge XAS spectra of free $\mathrm{C} f^{\mathrm{III}}$ and $\mathrm{Pc} \mathrm{c}^{\mathrm{I}}$-bound $\mathrm{C} f^{\mathrm{II}}$. Experimental data for $\mathrm{C} f^{\mathrm{III}}$ and $\mathrm{Pc}^{\mathrm{I}}-\mathrm{C} f^{\mathrm{II}}$ are shown in continuous and dashed lines. The presence of a pre-edge signal at $7113 \mathrm{eV}$ is marked by arrows

This tiny perturbation is consistent with the intensity changes at the pre-edge region of $\mathrm{C} f{ }^{\mathrm{II}}$ in presence of $\mathrm{Pc}^{\mathrm{I}}$, because they correspond to transitions to the iron $d_{\mathrm{z}} 2$ and $d_{\mathrm{x}} 2 \mathrm{y} 2$ orbitals, which are pointing towards the axial and equatorial ligands, respectively. As the reducing electron is not located in these orbitals, such subtle changes may have little influence on the redox potential. This situation is clearly different to that previously reported for cytochrome $c_{6}$, which shows a perturbation on the pre-edge region corresponding to its oxidized species, instead of the reduced ones, upon binding its reaction partner, photosystem I (Díaz-Moreno et al. 2006). In such case the pre-edge corresponds to transfer to a half-occupied non-bonding $d$ orbital, which is that receiving the reducing electron, so the observed changes can be correlated with changes in the redox potential of the heme protein. Regarding to this point, it is important to note that the heme plane is normal to the interaction surface of cytochrome $c_{6}$, but parallel in the case of $\mathrm{C} f$.

Thus, our results indicate that the bond between iron and the $\mathrm{N}$-terminus nitrogen is strong enough to prevent a distortion of the iron-coordination geometry upon binding of $\mathrm{C} f$ to $\mathrm{Pc}$, as well as to provide a stable binding site to the copper protein. Such a stiffness of the coordination sphere minimises the reorganisation energy concomitant to charge transfer, thus optimising the ET process.

Acknowledgements This work was supported by the European Synchrotron Radiation Facility (ESRF SC-1366), the Spanish Ministry of Education and Science (AP2000-2937, BMC2003-00458 and MAT02-01221) and the Andalusian Government (PAI, CVI-0198). 


\section{References}

Albarrán C, Navarro JA, Molina-Heredia FP, Murdoch PS, De la Rosa MA, Hervás M (2005) Laser flash-induced kinetic analysis of cytochrome $f$ oxidation by wild-type and mutant plastocyanin from the cyanobacterium Nostoc sp PCC 7119. Biochemistry 44:11601-11607

Allen JF (2004) Cytochrome $b_{6} f$ : structure for signalling and vectorial metabolism. Trends Plant Sci 9:130-137

Carrel CJ, Schlarb BG, Bendall DS, Howe CJ, Cramer WA, Smith JL (1999) Structure of the soluble domain of cytochrome $f$ from the cyanobacterium Phormidium laminosum. Biochemistry 38:9590-9599

Cheng MG, Rich AM, Armstrong RS, Ellis PJ, Lay PA (1999) Determination of iron-ligand bond lengths in ferric and ferrous horse heart cytochrome $c$ using multiple-scattering analyses of XAFS data. Inorg Chem 38:5703-5708

Coleman PM, Guss JM, Sugimura Y, Yoshizaki FY, Freeman HC (1978) Crystal structure of plastocyanin from a green alga, Enteromorpha prolifera. J Mol Biol 211:617-632

Díaz-Moreno I, Díaz-Quintana A, De la Rosa MA, Ubbink M (2005a) The orientation of plastocyanin in the complex with cytochrome $f$ from the cyanobacterium Nostoc determined by paramagnetic NMR. J Biol Chem 280:18908-18915

Díaz-Moreno I, Díaz-Quintana A, De la Rosa MA, Crowley PB, Ubbink M (2005b) Different modes of interaction in cyanobacterial complexes of plastocyanin and cytochrome $f$. Biochemistry 44:3176-3183

Díaz-Moreno I, Díaz-Quintana A, Subías G, Mairs T, De la Rosa MA, Díaz-Moreno S (2006) Detecting transient proteinprotein interactions by X-ray absorption spectroscopy: the cytochrome $c_{6}$-photosystem I complex. FEBS Lett 580:3023-3028

Díaz-Quintana A, Navarro JA, Hervás M, Molina-Heredia FP, De la Cerda B, De la Rosa MA (2003) A comparative structural and functional analysis of cyanobacterial plastocyanin and cytochrome $c_{6}$ as alternative electron donors to Photosystem I. Photosynth Res 75:97-110

Gough J, Chotia C (2004) The linked conservation of structure and function in a family of high diversity: The monomeric cupredoxins. Structure 12:917-925

Gray JC (1992) Cytochrome $f$ : structure, function and biosynthesis. Photosynth Res 34:359-374

Hervás M, Navarro JA, De la Rosa MA (2003) Electron Transfer between Membrane Complexes and Soluble Proteins in Photosynthesis. Acc Chem Res 36:798-805

Hope AB (2000) Electron transfers amongst cytochrome $f$, plastocyanin and photosystem I: Kinetics and mechanisms. Biochim Biophys Acta 1456:5-26
Lange C, Cornvik T, Díaz-Moreno I, Ubbink M (2005) The transient interaction of poplar plastocyanin with cytochrome $f$ studied by 2D-NMR spectroscopy: effects of ionic strength and $\mathrm{pH}$. BBA Bioenergetics 1707:179-188

Martinez SE, Huang M, Szczpaniak A, Cramer WA, Smith JL (1994) Crystal structure of chloroplast cytochrome $f$ reveals a novel cytochrome fold and unexpected heme ligation. Structure 2:95-105

Molina-Heredia FP, Hervás M, Navarro JA, De la Rosa MA (1998) Cloning and correct expression in Escherichia coli of the pet $\mathrm{E}$ and pet $\mathrm{J}$ genes respectively encoding plastocyanin and cytochrome $c_{6}$ from the cyanobacterium Anabaena $s p$. PCC 7119. Biochem Biophys Res Commun 243:302-306

Musiani F, Dikiy A, Semenov AY, Ciurli S (2005) Structure of the intermolecular complex between plastocyanin and cytochrome $f$ from spinach. J Biol Chem 280:18883-18841

Newville M, Ravel B, Haskel D, Rehr JJ, Stern EA, Yacoby Y (1995) Analysis of multiple-scattering XAFS data using theoretical standards. Physica B 208\&209:154-155

Redinbo MR, Yeates TO, Merchant S (1994) Plastocyanin: structural and functional analysis. $\mathrm{J}$ Bioenerg Biomembr 26:49-66

Rehr JJ, Zabinsky SI, Albers RC (1992) High-order multiple scattering calculations of $\mathrm{x}$-ray-absorption fine structure. Phys Rev Let 69:3397-3401

Sandman G, Reck H, Kessler E, Böger P (1983) Distribution of plastocyanin and soluble plastidic cytochrome $c$ in various classes of algae. Arch Microbiol 134:23-27

Schnackenberg J, Than ME, Mann K, Wiegand G, Huber R, Reuter W (1999) Amino acid sequence, crystallization and structure determination of reduced and oxidized cytochrome $c_{6}$ from the green alga Scenedesmus obliquus. J Mol Biol 290:1019-1030

Shulman RG, Yafet T, Eisenberger P, Blumberg WE (1976) Observation and interpretation of X-ray absorption edges in iron compounds and proteins. Proc Natl Acad Sci USA 73:1384-1388

Sykes AG (1985) Tilden Lecture: Structure and Electron-transfer Reactivity of the Blue Copper Protein Plastocyanin. Chem Soc Rev 14:283-315

Ubbink M (2004) Complexes of photosynthetic redox proteins studied by NMR. Phosynth Res 81:277-287

Westre TE, Kennepohl P, DeWitt JG, Hedman B, Hodgson KO, Solomon E (1997) A multiplet analysis of the Fe K-edge 1s-3d pre-edge features of iron complexes. J Am Chem Soc 119:6297-6314 